\title{
The 12 base pair duplication/insertion alteration could be a regulatory mutation
}

Mercedes Robledo, Ana Osorio, Carlos Sentís, José Albertos, Laura Estevez, Javier Benítez

\begin{abstract}
A wide array of mutations now numbering more than $\mathbf{2 0 0}$ have been identified in the BRCA1 gene, one of the two breast cancer susceptibility genes identified so far. In addition, there have been several variants described but it is not known if they really represent functionally significant mutations of the BRCA1 gene. We report evidence to show that the duplication/ insertion of 12 base pairs in intron 20 could have a real effect on expression of the BRCA1 gene, although it was also present in $1 \%$ of our control population. (F Med Genet 1997;34:592-593)
\end{abstract}

Keywords: BRCA1 gene; duplication; insertion

BRCA1 is one of the two breast cancer susceptibility genes identified so far. A wide array of mutations now numbering more than 200 have been identified in the BRCA1 gene. ${ }^{12}$ In addition, several variants have been described but it is not known if they really represent functionally significant mutations of the BRCA1 gene. ${ }^{34}$ We report here a case of an insertion of 12 base pairs (bp) in intron 20. We give additional evidence to show that this variant could have a real effect on the expression of BRCA1.

The insertion of $12 \mathrm{bp}$ in intron 20

Gepartamento de Jiménez Díaz, Avenida Reyes Católicos 2, 28040 Madrid, Spain M Robledo

A Osorio

J Benítez

Unidad de Genética, Departamento de Biología, Facultad de Ciencias, Universidad Autónoma de Madrid, 28034 Madrid, Spain C Sentís

Servicio de Cirugia, Hospital Ruber, Madrid, Spain J Albertos

Departamento de Oncología, Fundación Jiménez Díaz, 28040 Madrid, Spain L Estevez

Correspondence to: Dr Robledo.

Received 30 June 1996 Revised version accepted for publication 31 January 1997 represents a tandem reduplication of the sequence 5' GTATTCCACTCC 3' that begins $48 \mathrm{bp}$ downstream of the 3 ' boundary of exon 20. This variant is easily detected by SSCP analysis, using PCR amplification of genomic DNA and cDNA primers previously described. ${ }^{5}$ PCR reaction was carried out in a volume of $50 \mu \mathrm{l}$ containing $100 \mathrm{ng}$ of DNA or cDNA, $200 \mu \mathrm{mol} / 1$ of each dATP, dGTP, and dTTP, $20 \mathrm{nmol} / 1$ of dCTP, $0.5 \mu \mathrm{Ci}$ of $\left[\alpha-{ }^{32} \mathrm{P}\right] \mathrm{dCTP}(300 \mathrm{Ci} / \mathrm{mmol}, \mathrm{ICN}), 50 \mathrm{pmol}$ of each primer, $0.1 \%$ Triton X100, $2 \%$ DMSO, 1 $\times$ PCR buffer, and 1 unit Taq polymerase (Boehringer Mannheim). Amplification was 35 cycles of $94^{\circ} \mathrm{C}$ for 45 seconds, $58^{\circ} \mathrm{C}$ for $30 \mathrm{sec}-$ onds, and $72^{\circ} \mathrm{C}$ for 30 seconds. Amplified samples were diluted 1:10 in formamide buffer and loaded into a SSCP gel for 14 hours in 0.5 TBE buffer at room temperature. PCR products were bidirectionally sequenced with DyeDeoxy terminator cycle sequencing kit (Applied Biosystems) according to the manufacturer's instructions.

In a routine collection of peripheral blood and tumour samples from patients with breast/ ovarian cancer, we found the $12 \mathrm{bp}$ duplication/insertion by SSCP and sequencing in a male with breast cancer aged 44 ; informed consent was obtained from each patient before tissue collection.

This variant has been previously described in four cases: a woman with both breast and ovarian cancer and a high risk family history, ${ }^{3}$ a young woman without a family history of cancer, ${ }^{4}$ and two men with prostate cancer with and without a family history respectively. ${ }^{6}$ In the last three cases the variant was not present in any of the subjects in the control population analysed. However, in all these studies the variant was considered as a definite mutation, although cDNA was not available for experiments to provide formal proof of an effect on RNA processing. Recently, this alteration has been described in Polish control subjects, causing more confusion about its significance.

Our patient does not have a family history of breast cancer, although the structure of his pedigree, with no females, only four brothers aged between 23 and 44, and only male second degree relatives, could be contributory. Therefore, we searched for this allele in the general

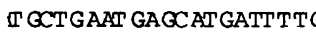

$190 \quad 200$
Figure 2 (A) Sequence across exon 13 from patient's genomic DNA showing heterozygosity at position 4427 . (B) Sequence across exon 13 from patient's cDNA showing a loss of heterozygosity at position 4427. 
population using DNA samples from 93 unrelated and anonymous parents of patients with cystic fibrosis, Duchenne muscular dystrophy, and myotonic dystrophy. As far as we know, they are not suspected of having any inherited predisposition to malignant conditions. We found the same variant in a male control subject, which represents approximately $1 \%$ of our population. These data were in agreement with those reported by Krzyzosiaka ${ }^{7}$ who found this variant in $2 \%$ of a Polish control population.

Although these initial results supported the idea that this alteration was not related to the disease, we were able to confirm that the insertion did not modify the correct splicing of exons 19-21, by analysing the cDNA obtained from the patient's peripheral blood. The fragments were amplified using primers that cover position 5092 to 5396 of the BRCA1 cDNA sequence (U14680) (from exon 19 to the end of the gene). The insertion seemed not to have any effect on the cDNA fragment size compared with a control subject. A sequencing across the boundaries of exons 19-21 from cDNA was performed to ensure that this alteration had not caused a more subtle splicing defect. In both cases, we only detected the normal BRCA1 sequence (fig 1).

As this subject was heterozygous for a common polymorphic site in BRCA1 exon 13 (4427C/T from genomic DNA), we also tested heterozygosity in cDNA from the patient using primers covering position $4323-4609$ of the BRCA1 gene cDNA sequence (U14680) and a surprising state of homozygosity was found (fig
2). This result would suggest that the intron 20 insertion creates an unstable transcript, having a real effect on BRCA1 expression.

Although we cannot draw conclusions, because we did not have blood samples from the patient's parents and we could not confirm if the insertion and the polymorphism on exon 13 were in the same chromosome or not, we think that this variant has an effect that leads to the appearance of an unstable transcript of one of the alleles of BRCA1. However, the description of the $12 \mathrm{bp}$ insertion in patients without a family history of breast cancer could suggest that this mutation has a low penetrance, and other genetic events or a specific haplotype would be required for the development of the disease.

This work was partially supported by DGICYT (Ref SAF 96-0192). Ana Osorio is a fellow of the Conchita Rábago Foundation.

1 Couch FJ, Weber BL. Breast cancer information core. Mutations and polymorphisms in the familial early onset breast cancer (BRCA1) gene. Hum Mutat (in press).

2 Szabo CI, King MC. Inherited breast and ovarian cancer. Hum Mol Genet 1995;4:181 1-17.

3 Takahashi H, Behbakht K, McGovern PE, et al. Mutation analysis of the BRCA1 gene in ovarian cancers. Cancer Res 1995;55:2998-3002.

4 Langston AA, Malone KE, Thompson JD, Daling JR, Ostrander EA. BRCAl mutations in a population-based sample of young women with breast cancer. $N$ Engl $\mathcal{F}$ Med 1996;334:137-42.

5 Friedman LS, Osterrneyer EA, Szabo CI, et al. Confirmation of BRCA1 by analysis of germline mutations linked to tion of BRCA1 by analysis of germline mutations linked to 8:399-404.

6 Langston AA, Stanford JL, Wicklund KG, Thompson JD, Blazej KG, Ostrander EA. Germ-line BRCAl mutations in selected men with prostate cancer. Am f Hum Genet 1996; 58:881-5.

7 Krzyzosiaka WJ. Breast information core. http:// www.nchgr.nih.gov/dir/lab_transfer/bic. 